\title{
ПАЛИНОЛОГИЧЕСКАЯ ХАРАКТЕРИСТИКА АЛЛЮВИАЛЬНЫХ ТОЛЩ ДОЛИНЫ РЕКИ БАРГУЗИН (РЕСПУБЛИКА БУРЯТИЯ)
}

\author{
С. В. Рассказов ${ }^{1}$, Т. Ф. Трегуб ${ }^{2}$, М. А. Волков ${ }^{2}$ \\ ${ }^{1}$ Иркутский государственный университет \\ ${ }^{2}$ Воронежский государственный университет
}

Поступила в редакцию 26 апреля 2019 г.

\begin{abstract}
Аннотация: в низовьях реки Баргузин изучались отложения аллювиальной формачии. Для обоснования хронологических рубежей накопления данных отложений пробурена скважина (545), которая вскрыла мощную толщу отложений. Палинологические исследования из настоящего разреза позволили уточнить и обосновать возраст отложений в рамках позднего палеогена и неогена. Детальное изучение палиноспектров обозначило интервал накопления осадков в пределах позднего олигоцена, миоцена и плиоцена.
\end{abstract}

Ключевые слова: Аллювиальнная формация, река Баргузин, палинологический комплекс, Палеоген, Неоген.

\section{PALYNOLOGICAL CHARACTERISTICS OF THE ALLUVIAL FORMATIONS OF THE VALLEY BARGUZIN RIVER}

\begin{abstract}
Barguzin river. In order to justify the chronological boundaries of the accumulation of bottom sediments. Was drilled well (545) which opened a powerful pack of sediments. Palynological studies of this section have helped to clarify and substantiate the age of the deposits within the framework of the late Paleogene and Neogene. A detailed study of the spectra indicated the interval of sedimentation within the Miocene and Pliocene.
\end{abstract}

Key words: Alluvial formation, Bargusin river, pallinological complex, Paleogene, Neogene.

Байкальская рифтовая зона является сложным геологическим объектом. Она заложилась в конце эоцена при столкновении Индо-Австралийской литосферной плиты с Евразийской. Развитие зоны происходило в олигоцене - квартере, сопровождаясь щёлочно-базальтовым вулканизмом (Тункинская впадина) и накоплением мощных толщ осадков. Основная фаза рифтогенеза с подъёмом плеч рифтов и формированием современного облика впадин и их горного обрамления приходится на конец неогена - начало квартера.

Позднекайнозойские осадочные и вулканогенноосадочные толщи Забайкалья изучались более 25 лет. Для кайнозоя Забайкалья долгое время имелись лишь рабочие варианты стратиграфических схем и фрагментарные данные палинологических исследований. Необходимость обоснования стратиграфической последовательности стратонов появилась в связи с созданием серийных легенд к геологическим картам нового поколения, на основе новых биостратиграфических данных с применением радиоизотопного датирования [1].

С целью расчленения аллювиальных отложений долины реки Баргузин была пробурена скважина
(545) юго-восточнее города Баргузин, которая вскрыла мощную пачку осадочных отложений, представленных в основном переслаиванием песчаников и алевролитов. При проведении палинологических исследований была поставлена цель - обосновать возраст отложений аллювиальной формации реки Баргузин. Для выполнения поставленной цели требовалось выполнить ряд задач: выделить палиноспектры из отложений скважины 545; проанализировать состав выделенных спорово-пыльцевых спектров; выделить палинозоны на основе изменения флористического состава палиноспектров; скоррелировать характеристики палинозон данного разреза с палинологическими материалами из стратотипических разрезов Западно-Сибирской низменности, Центрально-Сибирского и Восточно-Азиатского регионов.

По полученным данным была построена споровопыльцевая диаграмма. Результаты палинологических исследований позволили выделить на ней четыре палинозоны, которые отразили сукцессионные ряды растительного покрова за время накопления аллювиальной пачки отложений (рис. 1). 


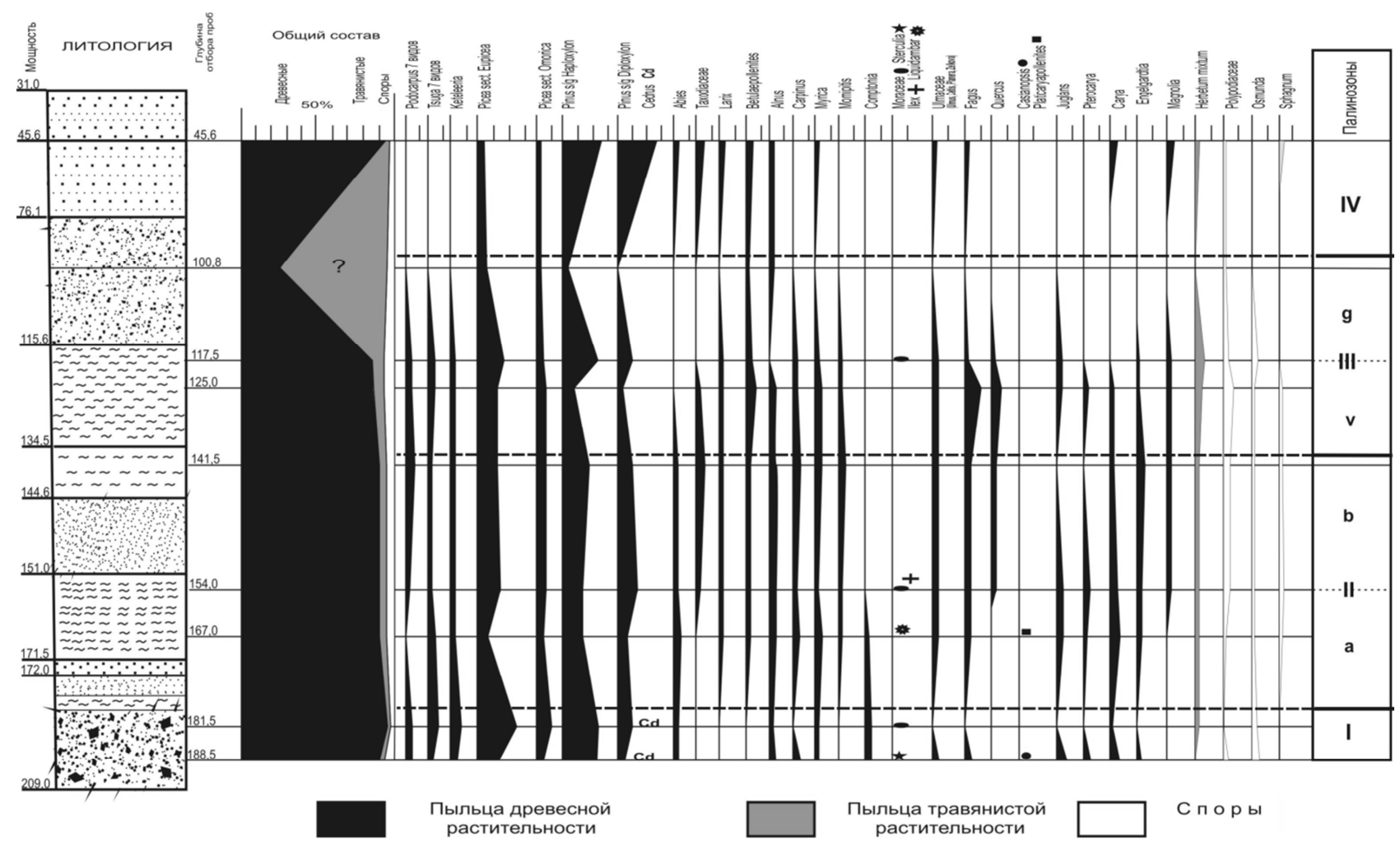

Puc. 1. Спорово-пыльцевая диаграмма скв. 545.

I палинозона включает пробы, взятые с глубин 188,5 и 181,5 м. Состав палиноспектров фиксирует преобладание пыльцы голосеменных с преобладанием Picea sect. Eupicea u sect. Omorica. Покрытосеменные представлены в малых количествах в основном в начале и в конце зоны. Пыльца травянистых растений представлена слабо и только в верхней части зоны. Споры малочисленны и слагаются представителями семейства чистоустовых (Osmundaceae). Обоснованием выделения зоны является наличие в составе голосеменных пород пыльцы рода Podocarpus, а также в составе покрытосеменных - пыльцы рода Comptonia. Пыльца родов Cedrus и Sterculia, вероятнее всего, присутствовала в составе спектров уже в качестве реликтов. Представители данных родов исчезают на границе позднего олигоцена раннего миоцена. На основании вышеизложенного отложения I палинозоны можно рассматривать как фрагмент последнего этапа олигоцена.

II палинозона включает пробы, взятые с глубины 167,0-141,5 м. Палинозона, как и предыдущая зона характеризуется преобладанием пыльцы голосеменных пород. Состав пыльцы покрытосеменных пород и его вариации позволил выделить в данной зоне две подзоны - $\mathbf{a}$ и $\mathbf{b}$. В целом для палинозоны характерно возрастание доли участия в составе спектров пыльцы теплолюбивых пород (Magnolia, Engelhardtia, Carya, Pterocarya, Juglans, Quercus, Fagus, Ulmus, Momipites, Myrica, Carpinus). В составе голосеменных пород появляется пыльца рода Larix и пыльца семейства Taxodiaceae. Состав выделенных палинофлор позво- ляет рассматривать возраст отложений в интервале $180-134,5$ м в объеме раннего миоцена.

Подзона а выделяется на основе максимальных значений таких родов как: Carya, Pterocarya, Juglans, Myrica, Carpinus, а также появлению пыльцы рода Momipites и исчезновению пыльцы рода Comptonia в составе палинокомплексов. Кроме этого, в данной подзоне отмечены зерна реликтов родов Liquidambar, Ilex и семейства Moraceae которые выше по разрезу не зафиксированы.

Подзона $\mathbf{b}$ выделяется на основе появления таких родов как: Taxodium, Quercus и Magnolia. Отмечается возрастание количества пыльцы Picea sect. Eupicea $u$ Pinus s/g Diploxylon.

Травянистые, как и в предыдущей зоне, представлены разнотравьем. Количество спор в начале зоны незначительно и представлены родом Osmunda. К концу зоны количество спор возрастает, и появляются представители двух семейств Polipodiaceae и Sphagnaceae. $[2,3]$

III палинозона объединяет пробы, взятые с глубин $125,0-100,8$ м. Зона характеризуется, как и предыдущие зоны, присутствием большого количества пыльцы голосеменных, но в отличие от первых двух, пыльца родов Podocarpus, Tsuga, Keteleeria здесь играет меньшую роль и исчезает в конце зоны. Покрытосеменные, как и в палинозоне II, разнообразны и представлены в достаточно большом количестве. Одним из признаков является появление, практически исчезнувших в конце второй зоны, представителей родов Juglans и Pterocarya, которые снова появляют- 
ся, достигая своего максимума, а выше по разрезу практически исчезают из состава палинокомплексов. Но главным аргументом выделения является пик пыльцы родов Fagus и Quercus, которые характеризуют теплый и довольно сухой климат. Травянистые так же представлены разнотравьем, но здесь они достигают максимума своего развития, это может быть связанно с освободившимися экологическими нишами. В составе спор отмечаются изменения. Споры семейств Polypodiaceae u Osmundaceae достигают своего максимума, но к концу зоны их ареал сокращается вплоть до полного исчезновения. Вышеописанный состав палинокомплексов хорошо коррелируется со спектрами в стратотипических разрезах для начальных фаз среднего миоцена

В III палинозоне на основе изменения состава палинокомплексов выделено 2 подзоны $\mathbf{v}$ и $\mathbf{g .}$

Подзона $\mathbf{v}$ выделяется на основании максимального значения пыльцы родов Quercus, Fagus. Так же увеличивается количество пыльцы мелколиственных древесных пород (Alnus и Betulaepollenites). Среди голосеменных уменьшается количество пыльцы рода Pinus.

Подзона $\mathbf{g}$ выделяется условно на основе резкой деградации группы покрытосемянных растений с последующим выпадением из состава практически всех теплолюбивых элементов. Значение пыльцы голосеменных пород уменьшается, и практически исчезают такие роды как: Podocarpus, Tsuga, Keteleeria.

Возможно, данный этап отразил переход от миоцена к плиоцену.

IV палинозона включает пробу, взятую с глубины 45,6 м. Зона характеризуется меньшим количеством пыльцы голосеменных по отношению к предыдущей зоне. Видовой состав пыльцы покрытосеменных резко беднеет, и остаются единичные представители лишь нескольких родов: Myrica, Ulmus, Fagus, Carya, Magnolia. Травянистые практически исчезают в начале зоны и появляются лишь в конце, но количество их минимальное. Споры отмечены в виде единичных зерен (первые проценты). Они представлены в основном, семейством Polypodiaceae и в конце зоны появляются представители рода Sphagnum.

На спорово-пыльцевой диаграмме получили отражение 4 крупных этапа развития растительности в течение накопления отложений данного разреза. На этой основе были скоррелированы хронологические границы накопления отложений аллювиальной формации в низовье течения реки Баргузин. Возраст отложений в интервале 209-181,5 м был обоснован и подтвержден палинологическими данными в рамках позднего олигоцена (I палинозона).

Осадки интервала 172,0-115,6 м предварительно датировались в широком диапазоне от миоцена до нижнего плиоцена. Палинологические материалы позволили уточнить возраст отложений. Время накопления данной пачки до глубины 141,5 м следует рассматривать в рамках начальных фаз нижнего миоцена (II палинозона). Верхняя часть интервала от 141,5 м до 100,8 м по палинологическим данным отвечает ранним стадиям среднего миоцена и выделяется в III палинозону. По предварительной датировке верхняя часть разреза (интервал 115,6-100,8 м) относится к верхнему плиоцену-эоплейстоцену. Палинологические исследования позволили на данном этапе изучения разреза рассматривать возраст интервала 100,8-45,6 м в объеме позднего миоцена-раннего плиоцена с выделением IV палинозоны.

\section{ЛИТЕРАТУРА}

1. Рассказов, С. В. Стратиграфия кайнозоя Витимского плоскогорья / С. В. Рассказов, Н. А. Лямина, Г. П. Черняева. - Новосибирск. Академическое издательство «Гео» 2007. $194 \mathrm{c}$.

2. Болотникова, М. Д. Спорово-пыльцевые комплексы третичных отложений западного побережья Японского моря / М.Д. Болотникова. - Издательство «Наука». 1979. - 196 с.

3. Томская, А. И. Палинология Кайнозоя Якутии / А. И. Томская. - Издательство «Наука» Сибирское отделение. 1981.- $224 \mathrm{c}$.

\section{Irkutsk State University}

Rasskazov S. V., Doctor of Geological and Mineralogical Sciences, Professor, senior researcher, head of the laboratory of isotopia and geochronology, Institute of the Earth's crust, SB RAS

E-mail:rassk@crust.irk.ru

Tel: 8 (3952) 511659

Voronezh State University

Tregub T. F., candidate of geographical Sciences, senior researcher

E-mail: ttregub108@yandex.ru

Tel.: +7 (432)2 208634

Volkov M. A., Postgraduate student of the Historical Geology and Paleontology Department, engineer

E-mail:1994vomaan@mail.ru

Tel.: +7 (432)2 208634 